\title{
Re-examining the Antarctic Paradox: speculation on the Southern Ocean as a nutrient-limited system
}

\author{
Julian Priddle, ${ }^{1}$ David B. Nedwell, ${ }^{2}$ Mighael J. Whitehouse, ${ }^{1}$ David S. Reay, ${ }^{2}$ Graham Savidge, ${ }^{3}$ \\ Linda C. Gilpin, ${ }^{3}$ Eugene J. Murphy, J. Cynan Ellis-Evans ${ }^{1}$ \\ ${ }^{1}$ British Antarctic Survey, Natural Environment Research Council, High Cross, Madingley Road, Cambridge CB3 OET, England \\ ${ }^{2}$ Department of Biology, University of Essex, Wivenhoe Park, Colchester CO4 3SQ, England \\ ${ }^{3}$ Marine Biological Station, Queen's University Belfast, Portaferry, Co. Down BT22 1PF, Northern Ireland
}

\begin{abstract}
The Southern Ocean is the largest of the high-nutrient, low-chlorophyll (HNLC) regions of the world ocean. Phytoplankton production fails to utilise completely the pool of inorganic nutrients in the euphotic zone, giving rise to low phytoplankton biomass and leaving relatively high summer nutrient concentrations. This enigma is of considerable significance for our understanding of the role of the oceans in the global carbon cycle. Various limiting factors have been considered: low light, low temperature, absence of necessary trace elements, grazing pressure and other means of biomass removal.

The dynamics of nitrogen uptake by phytoplankton are of particular importance. Classically, nitrate mixed into the surface layer during winter provides the nitrogen pool for growth in the spring bloom. Some organic material is exported to depth, whilst the remainder is recycled, providing ammonium and other reduced species as nitrogenous substrates for growth during the remainder of the season. The oxidation state of the inorganic nitrogen supply thus identifies new and recycled carbon fixation. Whilst this is convenient "shorthand" for the nitrogen nutrition of carbon export in much of the ocean, it is an inappropriate model for the Southern Ocean. Here, nitrate and ammonium use are simultaneous, and nitrate is never exhausted by the annual phytoplankton production.

We speculate that a range of environmental factors combine to make the large pool of nitrate partially inaccessible to phytoplankton. In addition to the documented effects of low iron availability and high ammonium concentrations, the low temperatures characteristic of the Southern Ocean may decrease nitrate availability because of the increased energetic overheads in its uptake and reduction. This in turn makes ammonium an important nitrogenous substrate, and its production by zooplankton and heterotrophic microorganisms is an important component of the plankton nitrogen cycle. There is some evidence that ammonium production by large grazing animals may stimulate phytoplankton growth. Microbial removal of nitrogen from sedimenting phytoplankton cells may result in local decoupling between the carbon and nitrogen cycles, allowing some reduced nitrogen to remain in the euphotic zone whilst carbon is exported to depth.
\end{abstract}

\section{INTRODUGTION}

This paper was prepared for a multidisciplinary symposium, and it was necessary to provide some background information for the non-specialist before moving on to the central theme of the paper. However, the paper is not intended to be a review, and reference is made to several other publications which provide more exhaustive coverage. Here, we wish to explore aspects of Southern Ocean biogeochemistry in the context of the global ocean carbon cycle, and introduce the concept of "bio-availability" to provide a standardised description of nutrient pools which represents their accessibility to phytoplankton under different environmental conditions. Some of our arguments are speculative, and are at present based on data from only few studies and sites, which may turn out not to be representative of the Southern Ocean as a whole. Most of the study sites are in the open ocean zone south of the Antarctic Polar Front and seas- onal-ice zone of the Southern Ocean, and it is these extensive areas to which our conclusions are applied.

\subsection{Background to the oceanic carbon cycle}

The oceans play an important role in the Earth's climate, and interact with the atmosphere in a number of ways. Whilst many mechanisms are purely physical, biological processes are also of key importance. For instance, phytoplankton may influence the thermal absorption of the upper ocean (Sathyendranath and others, 1991) and of sea ice (Zeebe and others, 1996). The area which has received most attention is the range of biological processes which produce materials which influence atmospheric properties, such as DMSPp (dimethylsulphonioproprionate) which contributes, through a series of chemical reactions, to cloud nucleation (e.g. Turner and others, 1996), and radiatively active or "greenhouse" gases (see SCOR, 1990). Many of 
these gases result in part from biological processes, the main examples being $\mathrm{CH}_{4}, \mathrm{~N}_{2} \mathrm{O}$ and especially $\mathrm{CO}_{2}$.

Carbon is stored in the ocean as dissolved $\mathrm{CO}_{2}$, as dissolved organic material and in particulate form as both organic and inorganic material. Various parts of the oceans act as sources of $\mathrm{CO}_{2}$ to the atmosphere, whilst other ocean regions are $\mathrm{CO}_{2}$ sinks where there is a net flux from atmosphere to ocean. In the source regions, $\mathrm{CO}_{2}$ concentration in surface water is oversaturated with respect to the atmosphere. This situation is commonly encountered where cold, $\mathrm{CO}_{2}$-rich water upwells in tropical regions. The sinks occur where $\mathrm{CO}_{2}$ in surface waters is undersaturated with respect to the atmosphere. This implies processes which are removing $\mathrm{CO}_{2}$ from the surface water. Some of these are physical, but biological processes also play an important role.

The so-called "biological pump" involves the sequestration of dissolved $\mathrm{CO}_{2}$ into organic material, and its subsequent export to the deep ocean (Longhurst, 1991). The first stage of this process is the fixation of carbon by microscopic, single-celled phytoplankton. These grow in the illuminated (euphotic) zone of the ocean, a layer which is typically $50-$ $150 \mathrm{~m}$ deep whereas the average ocean depth is of the order of $3.8 \mathrm{~km}$. The phytoplankton form the food supply for a range of small herbivorous animals, which in turn support a complex food web culminating in large predators. Most of the phytoplankton carbon which enters the food web is destined to be used as an energy supply, and this respiration puts $\mathrm{CO}_{2}$ back into the water (or directly into the atmosphere). However, a small proportion of the $\mathrm{CO}_{2}$ sequestered by the phytoplankton is exported from the euphotic zone to the deep ocean as either particulate or dissolved organic material. This represents carbon which is removed from the atmosphere on time-scales of hundreds to thousands of years.

\subsection{Carbon export, nutrient supply and HNLG regions}

Whilst phytoplankton share with land plants the ability to fix $\mathrm{CO}_{2}$ into organic material, using light energy, there are important differences between the two systems as photosynthetic environments. In the atmosphere, $\mathrm{CO}_{2}$ is a relatively scarce component, and experiments on the effects of elevated $\mathrm{CO}_{2}$ concentrations commonly show a stimulating effect. This implies that land plants may often be carbonlimited, although clearly other factors may also inhibit growth. In the oceans, $\mathrm{CO}_{2}$ is thought not to be limiting (although see Riebesell and others, 1993; Hein and SandJensen, 1997) and other environmental factors are likely to limit the rate of growth. We will examine these in the context of the Southern Ocean later in the paper. However, we need first to establish the role of other chemical elements in the growth of phytoplankton, in order to understand the importance of inorganic nutrients.

Phytoplankton obtain their carbon by "fixing" $\mathrm{CO}_{2}$ by the process of photosynthesis. However, they require a wide range of other elements for growth, such as nitrogen and phosphorus (and silicon for some groups). Within certain limits, these are incorporated into new cellular material in fixed ratios (Redfield and others, 1963). For example, a phytoplankton cell will contain about 15 atoms of nitrogen for every 100 atoms of carbon. Whereas the large reservoir of dissolved inorganic carbon in the surface ocean can be replenished by influx of $\mathrm{CO}_{2}$ from the atmosphere, other chemical nutrients are typically introduced to the upper layer of the open ocean predominantly by entrainment of nutrient-rich deep water. This is, of course, not necessarily the case in coastal water where run-off and flux from the seabed provide important nutrient supplies.

Since the euphotic zone is shallow, the overall quantity of inorganic nutrients contained within it will be relatively small. On this basis, the amount of inorganic nutrient supplied to the euphotic zone, predominantly at the beginning of the growing season, determines the maximum amount of phytoplankton production. Additional carbon cannot be fixed without further nitrogen or phosphorus supply. In most regions of the ocean, the pool of inorganic nutrient in the euphotic zone is used up within the growth season, usually soon after growth starts in the spring. A part of this production contributes to carbon export to deep water. Subsequent phytoplankton production involves the recycling of both nutrients and carbon within the euphotic zone. By definition, carbon cannot be exported under these conditions.

This pattern of early nutrient depletion followed by a recycling community is not followed in some parts of the ocean. Here, high nutrient concentrations persist throughout the year, but phytoplankton production is low. These are the high-nutrient, low-chlorophyll (HNLC) regions, of which the Southern Ocean is the most extensive (Longhurst and others, 1995). Such regions have special significance, because they are areas where there is potential for enhanced biological carbon sequestration, since the availability of other nutrients such as nitrogen or phosphorus does not determine the present upper limit for production. Enhanced production could thus bring about greater drawdown of atmospheric $\mathrm{CO}_{2}$. Crude calculations, based on nutrient availability but neglecting subsequent recycling, indicate that the nutrient supply in the Southern Ocean could sustain phytoplankton growth broadly equivalent to the $3 \times 10^{15} \mathrm{~g} \mathrm{Ca}^{-1}$ net global increase in atmospheric $\mathrm{CO}_{2}$ content (Davies, 1990). However, modelling studies indicate that complete nutrient utilisation within the Southern Ocean could have significant repercussions elsewhere. Sarmiento and Orr (1991) suggested that whilst the full potential primary production in the Southern Ocean would result in greater flux of organic matter in the oceans, concomitant nutrient reductions would decrease production in other parts of the ocean, and increased nutrient content at depth would result in anoxia in parts of the deep ocean (see also Peng and Broecker, 1991). Clearly, an understanding of the HNLC regions, and specifically of what controls nutrient availability, is of significant importance.

\section{THE SOUTHERN OCEAN AS AN HNLC SYSTEM}

At first sight, the Southern Ocean appears to be an unexpectedly productive system. Despite the short summer season and low temperatures, there is a wealth of marine animal life. Indeed, it was the exploitation of stocks of whales, seals and sea birds which stimulated much of the early exploration of Antarctica. However, subsequent direct measurements of the productivity of phytoplankton indicated that overall this is low (El-Sayed, 1984; Priddle and others, 1992). It appears that short, efficient food-chains enable low phytoplankton production to support high top predator production (Priddle and others, in press).

Low phytoplankton production in the Southern Ocean 
results in low rates of removal of inorganic nutrients. For example, the summer concentrations of dissolved nitrate are as high as those preceding the spring bloom in the North Atlantic. Here, we wish to explore the concept of the Southern Ocean as a typical HNLC system, and to examine the nutrient uptake dynamics which lead to this inability to utilise resources. We will focus on nitrogen as the major inorganic nutrient source, partly because it is a key nutrient which is required in quantities approaching the demand for carbon by all groups of phytoplankton, and partly because the different sources of nitrogen can be identified by the chemical species used (reduced vs oxidised sources).

Understanding of the functioning of HNLC systems must be predicated on an appreciation of the factors which might limit phytoplankton production, and hence their ability to remove nutrients from the pool existing at the start of the growing season. The growth of phytoplankton results from a combination of intrinsic growth rate and biomass (standing stock), and is often modelled using a simple exponential equation of the form:

$$
P_{t}=P_{0} \exp k t
$$

where $P_{t}$ and $P_{0}$ are biomass at time $t$ and time "zero", respectively, and the parameter $k$ is a function of doubling time. Factors which determine production may be either those which affect intrinsic growth rate (e.g. the availability of a specific substrate, influencing $k$ in the growth equation) or those which control the amount of phytoplankton (e.g. removal by grazing which will reduce $P$ ). Thus the net production of phytoplankton results from the balance between growth $(k)$ and loss $(l)$ :

$$
\frac{\mathrm{d} P}{\mathrm{~d} t}=k P-l P
$$

\subsection{Factors limiting phytoplankton growth in the Southern Ocean}

Factors affecting phytoplankton production in the Southern Ocean have been studied since the Discovery investigations in the 1930s, when scientists studied phytoplankton ecology and growth within a programme of research into the pelagic ecosystem connected with the whaling industry (Hart, 1934). However, no clear consensus has emerged, and it is becoming clear that we need to understand the interaction of a complex of factors (see also Hart, 1934; Banse, 1996). These can be classified into three main groups.

\section{Factors affecting $k$ : (1) energy}

The energy supply for phytoplankton growth is light, which enables organic material to be accumulated through photosynthesis. The light level experienced by phytoplankton is modulated by various environmental factors, varying over different time-scales ranging from the seasonal cycle to short-term changes in cloud or ice cover. In the ice-free Southern Ocean, wind-mixing of the surface layer has been shown to be of particular importance, because phytoplankton cells may be transported to depths where irradiance is too low to sustain growth. Such limitation has been demonstrated clearly (e.g. Mitchell and Holm-Hansen, 1991), and high phytoplankton biomass is commonly associated with locations where water-column stability is high (see Priddle and others, 1992).

A second energy limitation may be provided by temperature. Typically, organisms have a temperature range within which a process such as growth is possible, and within this range is an optimum temperature at which the process rate is maximal. The rate decreases at temperatures below this optimum. Although thermal adaptation is possible, it does not appear to be complete, and phytoplankton growth rates typically decrease with reduction in environmental temperature (Eppley, 1972; Raven and Geider, 1988). For the Southern Ocean, ambient temperature is uniformly low. Although phytoplankton growth rates may be near those thought to be maximal, there is a demonstrable effect of low temperature (Tilzer and others, 1986). However, this does not appear to preclude high biomass accumulation, for instance in areas where sea ice has just melted (e.g. Smith and Gordon, 1997). The effects of temperature on specific processes, rather than on growth rate as a whole, will be examined in more detail later.

\section{Factors affecting $k:$ (2) nutrients}

The second resource which can potentially limit growth rate is the availability of other chemical elements necessary for growth and maintenance. "Macronutrients" such as nitrogen, phosphorus and silicon are thought normally to be present throughout the Southern Ocean at concentrations significantly higher than those considered limiting for growth, although local reduction to low concentrations has been documented (Jennings and others, 1984; Priddle and others, 1995; Whitehouse and others, 1996). There is also evidence that the ability of phytoplankton to utilise some elements may be relatively inefficient, so that the apparently high concentrations present in the Southern Ocean may not be saturating for growth. For instance, it has long been known that Southern Ocean diatoms do not grow well on low concentrations of silicate (Jacques, 1983). It has been suggested that temperature effects on the equilibrium kinetics of silicic acid may imply that less of the inorganic silicon pool is biologically available ("bio-available") at low temperatures (Priddle and others, 1986).

In addition to the abundant elements which contribute to cell material, phytoplankton also require a range of trace elements which typically play a role in cellular processes, usually as components of enzyme molecules. These "micronutrients" are required only in very small quantities, but are often very scarce in the environment and may therefore be present at concentrations which limit growth rate. Recently, attention has focused on the importance of iron, which is the most abundant element in the planet, and the fourth most abundant element in the Earth's crust, but is present in most of the ocean at nanomolar concentrations $\left(10^{-9} \mathrm{~mol} \mathrm{l}^{-1}\right)$. Iron plays an important role in several biochemical systems, including electron transport and conversion of oxidised nitrogen sources to reduced species. The possibility that low iron availability may be important in large-scale ocean biogeochemistry was advanced by Martin (1990). There is experimental evidence that iron is present at limiting concentrations over much of the Southern Ocean (Löscher and others, 1997), and differences in distribution of dissolved iron have been implicated in spatial pattern of phytoplankton production (de Baar and others, 1995). In the Equatorial Pacific, another HNLC region, large-scale additions of iron to the upper ocean have stimulated phytoplankton blooms (Coale and others, 1996), but such ecosystem manipulations have not yet been attempted in the Southern Ocean. 
Factors affecting $P$

We distinguished above between controls on growth ratethe parameter $k$ in the exponent of the growth equationand control by removal of biomass, $P$. Grazing has been the major factor considered in this context, but is one of several means of removing phytoplankton biomass over a range of time-scales. Over the annual cycle, processes removing phytoplankton biomass must balance production, or the upper ocean would become clogged with algae. The interactions are complex, and phytoplankton production can be self-limiting through self-shading (Tett, 1990). Under some conditions, grazing can be very tightly coupled to phytoplankton production, and most phytoplankton material is then recycled. This is typical of communities where the phytoplankton is dominated by small-celled species, and the grazers are also single-celled organisms whose growth rate is fast enough to respond rapidly to changes in phytoplankton biomass (Capriulo and others, 1991). Phytoplankton blooms are typically dominated by larger cells, which are grazed by animals whose generation times are significantly longer than that of their food supply. Under these conditions, grazing pressure is highly patchy in both time and space (Priddle and others, 1990). Nevertheless, grazing by large animals such as krill and salps can be very effective in removing phytoplankton biomass, and the different types of grazers impose different behaviours on the ecosystem as a whole (Loeb and others, 1997). There may also be positive feedback from grazing to phytoplankton growth through the resupply of nutrients (Priddle and others, 1997).

Phytoplankton biomass may also be removed by physical mechanisms. Sedimentation can be an important loss process for phytoplankton under some circumstances, and is important biogeochemically because it is a means to transfer large amounts of particulate organic material to depth (Rice and others, 1986; Whitehouse and others, 1996). Recently, T. Platt and others (personal communication, 1997) modelled the effects of episodic deepening of the mixed layer by storm events. They suggested that this physical mechanism will both remove biomass and entrain nutrients, resulting in continuing HNLC conditions.

Except for the latter, the potential of all of these factors to control phytoplankton production in the Southern Ocean has been supported by observation. It is not our purpose to arbitrate between them - indeed we consider that a multifactoral model which incorporates all is likely to be needed - but we wish now to re-examine the Southern Ocean as an HNLC system against the background of these controls. We will look in particular at nitrogen cycling, as a pivotal element in our understanding of biogeochemical cycles in the ocean. In order to do this, we first examine the basic physiology of nitrogen use by phytoplankton.

\section{NITROGEN USE BY PHYTOPLANKTON}

\subsection{Physiological requirements}

We will consider the use of two forms of inorganic nitrogen, namely, ammonium $\left(\mathrm{NH}_{4}{ }^{+}\right)$and nitrate $\left(\mathrm{NO}_{3}{ }^{-}\right)$, as nitrogen substrates for phytoplankton (Flynn, 1991; Flynn and others, 1997), although phytoplankton may also use other nitrogen compounds, including some simple organic compounds such as urea. Inorganic nitrogen use within the phytoplankton cell is in the form of ammonium. The ionised form ammonium predominates in the ocean. Non-ionised ammonia may enter the cell by passive diffusion, but the low concentration probably makes this an unimportant substrate. The transport of ammonium (ionised) entails energetic cost, but once within the cell the substrate is in a form in which it can be incorporated directly into organic material.

Nitrate also requires active transport into the cell, and this may be energetically more expensive for the negatively charged ion than for positively charged ammonium (personal communication from K. Flynn, 1997). Once within the cell, nitrate is reduced first to nitrite and then to ammonium. This entails further energetic costs, both the direct expenditure on the reduction process and the additional costs associated with enzyme synthesis. The pathways and feedbacks in phytoplankton nitrogen uptake and incorporation are described by Flynn and others (1997).

An indication of the overall energy requirements for growth on the different substrates is provided by the measurement of photosynthetic quotient, $\mathrm{PQ}$ which is the ratio between the amount of oxygen generated by photosynthesis (itself related to the light energy fixed) and the amount of inorganic carbon taken up (growth). Phytoplankton grown on ammonium as the nitrogen substrate show lower values of PQ than those grown on nitrate (Williams and others, 1979; Williams and Robertson, 1991). Pragmatically, we would expect ammonium to be preferred to nitrate as the substrate for phytoplankton growth, given the distinct energy advantages for the reduced nitrogen source.

\subsection{Relationship between physiological require- ments and nitrogen supply in the surface ocean}

The chemical and biochemical processes which determine the character of the inorganic nitrogen supply in the surface ocean are complex, resulting in short-time-scale transformations between oxidised and reduced forms. Superimposed upon these surface layer processes is a long-term, large-scale pattern of nitrogen cycling between the surface and deep ocean, which supplies the bulk of the inorganic nitrogen for phytoplankton growth. Organic material in the deep ocean (which originated as phytoplankton production close to the surface) is remineralised to produce nitrate. This is introduced to the mixed layer through upwelling, and through the entrainment of deeper, nitrate-rich water during deep vertical mixing, which occurs predominantly during winter when stratification is weak. As a result, nitrate concentrations in the Southern Ocean surface mixed layer at the start of the phytoplankton growing season are typically $25-40 \mathrm{mmol} \mathrm{m}^{-3}$ (Smith, 1991; Priddle and others, in press).

By contrast, the concentrations of reduced forms of nitrogen, such as ammonium and nitrite, are relatively low. Fewer data are available for the Southern Ocean, but typical summer concentrations are in the range $0.1-2 \mathrm{mmol} \mathrm{m}^{-3}$ (Koike and others, 1986; Smith, 1991; Priddle and others, 1997). This pool of reduced nitrogen results from a range of biological processes taking place within the mixed layer, and has a much shorter turnover time than the nitrate supply.

In section 3.1, we noted that ammonium is the "preferred" nitrogen source for phytoplankton, in the teleological sense that it costs phytoplankton less energy to use ammonium than to use nitrate. However, for much of the Southern Ocean it is likely that $>90 \%$ of the inorganic nitrogen supply will be in the form of nitrate. There is clearly a mismatch between our interpretation of the phytoplankton's 
likely preference and what is available. This is not unique to the Southern Ocean, and is the situation which confronts phytoplankton in spring everywhere in the ocean. However, for the Southern Ocean and other HNLC environments, the phytoplankton seem unable to utilise nitrate effectively, and this resource is not used fully. Despite the predominance of nitrate, this only supplies around half of nitrogen nutrition for Southern Ocean phytoplankton (Priddle and others, in press).

Consideration of the use of nitrate and ammonium by phytoplankton is central to our understanding of the sequestration of atmospheric carbon dioxide by the "biological carbon pump" in the ocean. Because chemical speciation allows us to identify the origin of nitrogen, we can divide phytoplankton production into that derived from nutrient upwelled from deep water, which represents a "new" input to the euphotic zone, and that recycled within the euphotic zone (Dugdale and Goering, 1967; Eppley and Peterson, 1979). The $f$-ratio, which is the share of nitrate in overall phytoplankton nitrogen nutrition, is taken to represent the proportion of "new" production in total primary production under these conditions. New production sets the upper limit to the export of material from the euphotic zone to the deep ocean, so that high $f$-ratio allows the potential for high carbon export, whereas low $f$-ratio indicates the predominance of in situ recycling of carbon, and thus little export.

\section{RE-EXAMINING THE ANTARCTIC PARADOX}

Investigation of HNLC systems has generally started from the premise that phytoplankton production is failing to use up an abundant nutrient supply which elsewhere would support greater production. For the Southern Ocean at least, and concentrating on nitrogen supply, we would wish to approach the system at three levels. First, we examine the inorganic nitrogen pool in the euphotic zone, and from consideration of factors determining preference between ammonium and nitrate suggest that the system is strongly reliant on the relatively scarce pool of recycled nitrogen. We then examine the main ways in which nitrogen is being recycled, and suggest that this recycling can be very tightly coupled to phytoplankton production. Finally, we test the possibility that recycled nitrogen may sustain phytoplankton production which contributes to carbon export.

\subsection{Is the nitrogen pool as large as it seems, and what determines nitrogen preference?}

We have reviewed the status of the Southern Ocean as an HNLC region, and demonstrated that measured concentrations of macronutrients such as nitrogen are indeed high. However, we need to ask whether these measured concentrations are biologically meaningful. In order to make valid comparison with other parts of the world ocean, including other HNLC regions, we need to represent nutrient concentrations in a way which reflects their availability to the phytoplankton.

The contrasts between the mechanisms of ammonium and nitrate utilisation suggest that the nitrate pool in the Southern Ocean may be less accessible than the ammonium. We have already noted some environmental factors which may cause the "bio-available" pool of nitrogen to be lower than that measured using chemical analysis. Iron limitation may be an effective control, because iron is required for both of the enzymesnitrate- and nitrite-reductase, although it is likely that other processes such as electron transport and chlorophyll synthesis have higher iron requirements (personal communication from K. Flynn and R. Geider, 1997). Temperature may also affect the ability to utilise nitrate, because of our suggested bias towards the "low-cost" option of acquiring ammonium, thereby avoiding the energetic cost of both transporting nitrate into the cell and reducing it to ammonium. Finally, high concentrations of ammonium may themselves result in a decrease in the use of nitrate (Glibert and others, 1982; Wheeler and Kokkinakis, 1990; Flynn, 1991).

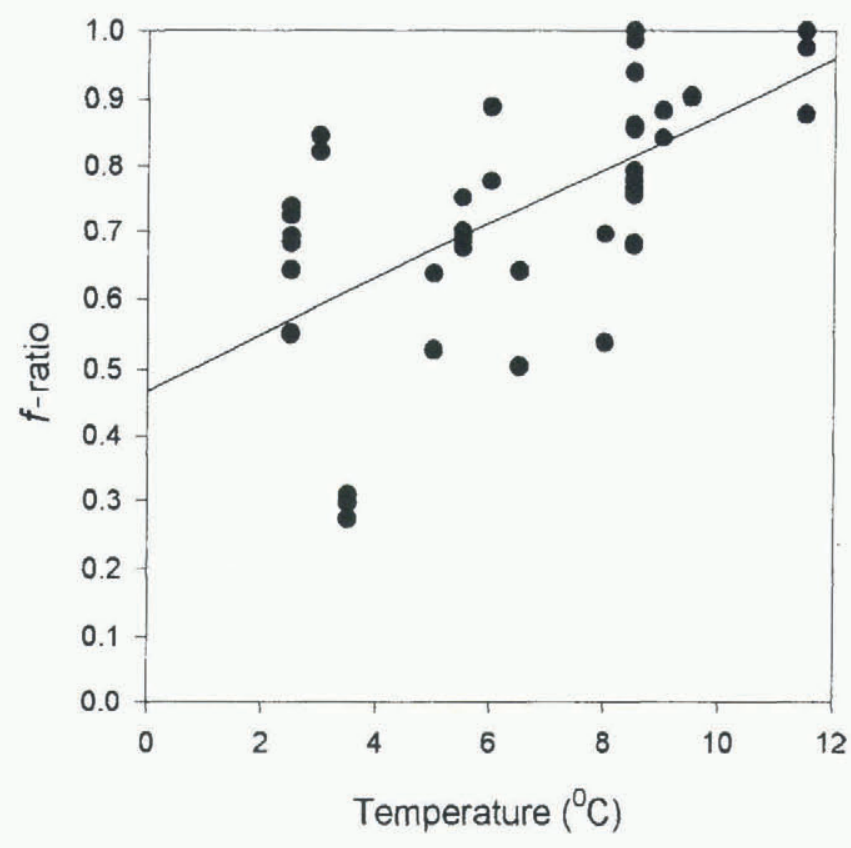

Fig. 1. Effect of temperature on the $f$-ratio (proportion of nitrate in overall nitrogen uptake) by natural communities of Southern Ocean plankton. Samples were collected from surface waters close to the Antarctic Polar Front, at temperatures of approximately $3-5.5^{\circ} \mathrm{C}$. These samples were then incubated under constant illumination $\left(\approx 200 \mu \mathrm{mol} \mathrm{m} \mathrm{m}^{-2}\right.$ fluorescent lighting) for 48 hours at ambient temperatures, ambient plus $3 K$ and ambient plus $6 K$. Values of $f$-ratio were calculated from depletion of nitrate and ammonium during the course of the experiments. The fitted regression line is significant $(P<0.001)$.

The role of temperature in determining nitrogen preference is an intriguing aspect, especially given the fact that it is an environmental control which might be alleviated by climatic change. As we have noted already, growth of phytoplankton on nitrate carries energetic overheads which do not apply, or at least not to the same extent, to growth on ammonium. We have suggested that the balance of inorganic nitrogen uptake will be shifted towards ammonium at low temperatures because the phytoplankton will have a lower capacity to support active processes. Laboratory studies of natural plankton populations from the Southern Ocean show that $f$-ratio increases with comparatively small increases in temperature, indicating that at low in situ temperatures nitrate uptake is inhibited (Fig. 1). Experiments on a variety of algal and bacterial isolates in culture have shown that temperature has a strong effect on nitrate 
uptake, but negligible effect on ammonium uptake, irrespective of the normal temperature range of the organism (Reay and others, unpublished information). So we can suggest that for much of the phytoplankton the very large supply of nitrate is of lesser relevance, and in our terms its bio-availability is lower than the measured concentrations suggest. These phytoplankton will be dependent on the resupply of ammonium through biological recycling, and therefore nitrogen regeneration within the euphotic zone becomes a crucial process for Southern Ocean phytoplankton production (Glibert and others, 1982; Priddle and others, 1997).

\subsection{What determines the resupply of ammonium within the euphotic zone?}

We noted above that nitrogen cycling within the euphotic zone involves a complex suite of biological processes. Here we highlight the resupply of ammonium, and in particular examine the plankton system close to South Georgia, Southwest Atlantic sector of the Southern Ocean, to highlight the importance of the two main processes at work.

Zooplankton are important grazers in the system, and appear to control phytoplankton biomass under some circumstances. They also regenerate ammonium through excretion. At South Georgia, Priddle and others (1997) showed that diurnal cycling of ammonium in surface waters is the result of the balance between daytime uptake by phytoplankton and night-time excretion by zooplankton. Circumstantial support for this hypothesis was provided by the loss of the diurnal pattern during years when krill, an important grazer in the system, was present at severely reduced biomass. Modelling the diurnal pattern, which in "krill" years showed an amplitude of $0.2-0.35 \mathrm{mmol} \mathrm{m}^{-3} \mathrm{~d}^{-1}$ over the upper $30 \mathrm{~m}$ of the water column, suggested that phytoplankton growth rate was high. To simulate the observed pattern, relatively high values for doubling time of 1-2 d were required. Priddle and co-workers speculate that the high rate of ammonium resupply may have stimulated production, introducing a positive feedback between grazers and their food supply.

Microbial recycling is also important in returning ammonium to the nitrogen pool in the euphotic zone (Glibert and others, 1982; Rönner and others, 1983), although heterotrophic bacteria are also competitors with phytoplankton for ammonium and other nitrogen sources (Hoch and Kirchman, 1995). Protozoan grazers will be more tightly coupled to the population dynamics of their food supply, and are likely to remineralise organic material more rapidly (Capriulo and others, 1991), with consequent reduction in Cand N-export. Therefore, although it is unlikely that they will contribute to the diurnal variation in ammonium production, they will account for the steady-state level of ammonium seen within the euphotic zone. For South Georgia, this value is around $0.4-0.6 \mathrm{mmol} \mathrm{m}^{-3}$ in all years sampled (Priddle and others, 1997), which suggests that microbial remineralisation is about equal to the maximum rate ascribed to zooplankton within the mixed layer. At the base of the mixed layer, a strongly developed ammonium (and sometimes also nitrite) maximum is found. This has been attributed to microbial activity (Priddle and others, 1995). This suggests that the pycnocline is the site of intense nitrogen recycling, which in turn may have impact on the material which is leaving the euphotic zone by sedimentation.

\subsection{Is carbon recycled along with nitrogen, or are nutrient cycles decoupled, allowing carbon export to be "fuelled" by reduced nitrogen?}

In describing the basic distinction between nitrate-fuelled new production and ammonium-fuelled recycled production, we noted that these descriptions imply that carbon and nitrogen are recycled in the same ratio as when the organic matter was formed. The recycling of nitrogen in the euphotic zone must then be accompanied by the return of organic carbon to the inorganic carbon pool.

On this basis, we would expect that material leaving the euphotic zone will have the same composition as when it was formed. For carbon and nitrogen, this implies a molar ratio of 6.625 (Redfield and others, 1963) or the 100 atoms to 15 atoms mentioned earlier. Observation confirms that particulate composition within the euphotic zone conforms to Redfield proportions. However, two Southern Ocean studies (Sambrotto and others, 1993; Priddle and others, 1995) indicate that the $\mathrm{C}: \mathrm{N}$ ratio may increase below the euphotic zone. In the case of the South Georgia system, particulate organic $\mathrm{C}: \mathrm{N}$ at $150 \mathrm{~m}$ depth had increased from around 7 to $11-12$ (Priddle and others, 1995). This indicates that nitrogen in sinking particles was being remineralised almost twice as fast as carbon. Such remineralisation is consistent with the ammonium peak in the pycnocline, and could result from the preferential breakdown of protein, which has a high nitrogen content, relative to lipid and carbohydrate (Smith and others, 1992).

The presence of this large pool of reduced nitrogen at the base of the euphotic zone offers the scope for returning nitrogen to the plankton production process, whilst carbon continues its journey to the deep ocean (Fig. 2). Both vertical diffusion and internal waves within the pycnocline would

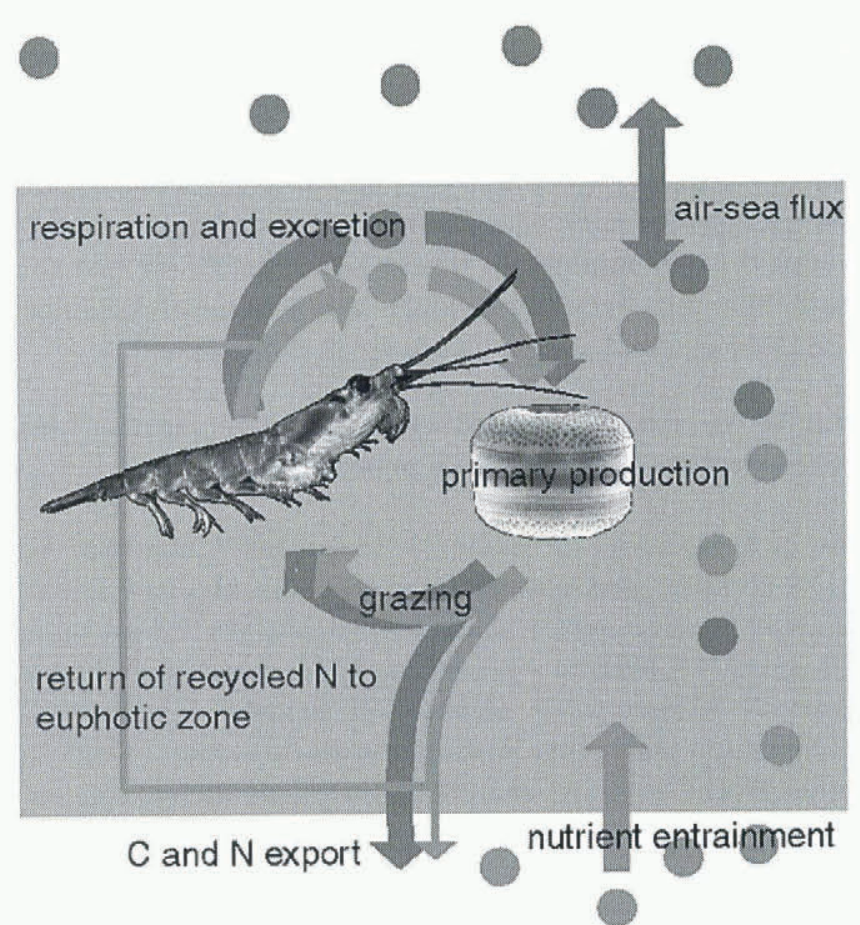

Fig. 2. Schematic illustration of coupling of the biological carbon and nitrogen cycles in the euphotic zone. The partial decoupling of nitrogen and carbon in sedimenting particles is shown, with the return of some nitrogen to the euphotic zone whilst carbon-rich material is exported to deep water. 
provide plausible mechanisms whereby ammonium stripped from sedimenting organic particulates could be returned to the euphotic zone. If these observations are indeed correct, then we have an apparent partial decoupling between the nitrogen and carbon cycles. This would allow particulate carbon to sediment to the deep ocean, whilst some nitrogen would be retained either within or immediately beneath the euphotic zone. The distinction between nitrate- and ammonium-fuelled primary production then becomes blurred. It is not possible tojudge whether this phenomenon is widespread, and whether carbon-rich material is exported to significant depth. The consensus is that the $\mathrm{C}: \mathrm{N}$ ratio in the deep ocean is close to Redfield (e.g. Copin-Montegut and Copin-Montegut, 1983), so that any imbalance is local or is adjusted within the upper few hundreds of metres.

\section{A RE-EVALUATION OF THE SOUTHERN OGEAN AS AN HNLG SYSTEM}

We defined HNLC systems on the basis of the two properties which provide the name, i.e. the simultaneous presence of high concentrations of the macronutrients ("HN") which typically become limiting for growth in much of the world ocean, and low phytoplankton biomass (as chlorophyll; "LC"). Attempts to understand these systems are typically framed in the form, "what is limiting the primary production?".

At a recent discussion of HNLC systems at a Joint Global Ocean Flux Study (JGOFS) modelling symposium, a more flexible definition of these environments was formulated. It was noted that the characteristics of HNLC systems could appear under a range of conditions, and indeed the grouping of the Southern Ocean, the sub-Arctic Pacific and the Equatorial Pacific in a single phenomenon is not an intuitively obvious one. What they share is a rate of annual nutrient supply to the euphotic zone which exceeds the annual removal of nutrients by primary production. This can occur under a range of circumstances, but is not necessarily always indicative of low primary production, nor is phytoplankton biomass always low. The discussion distinguished between two extreme behaviours. The first could be represented as high-nutrient, low-production, low-biomass (HN-LP-LC). This is the "classic" HNLC system where annual primary production is too low to remove the wintertime input of nutrients. It can be regarded as a "deviant" version of the situation which obtains in areas like the North Atlantic, where in the latter case primary production in the spring bloom is sufficient to utilise fully the wintertime nutrient input.

However, some HNLC systems, including much of the Southern Ocean, are upwelling systems where nutrient input to the euphotic zone is not simply a seasonal event. Such systems could be more productive, although this production may not always "keep up" with the supply of nutrients. The dynamics of high-nutrient, high-production, low-biomass (?) (HN-HP-LC) systems will be different from those of their low-production relatives. In particular, they provide the scope for high export of particulate material. This is observed for parts of the Southern Ocean, where a comparatively large fraction of surface production reaches the sea-floor by sedimentation (data from the KERFIX study; personal communication from P. Pondaven and others, 1997).
The Southern Ocean is a mosaic of HN-LP-LC and HNHP-LC systems. Overall, it seems that both physical-chemical and biochemical factors restrict the "bio-availability" of macronutrients, so that the high concentrations determined by chemical analysis may not accurately represent the pools available for phytoplankton production. In particular, the high levels of nitrate may not be accessible if low temperature and low iron availability mean that the ability of phytoplankton to use nitrate is reduced.

Given the dependence on recycled nitrogen sources for phytoplankton growth in the Southern Ocean, the rate at which this relatively scarce nutrient is resupplied becomes critical. In this sense, nitrogen - as low concentrations of ammonium and higher concentrations of less "accessible" nitrate - can be considered as a limiting nutrient, in relation to other inorganic nutrients such as phosphorus and silicon, in parts of the Southern Ocean.

The close coupling between phytoplankton growth and nitrogen remineralisation provides the scope for strong feedbacks between grazing control and primary production. Although grazing may exert strong control on phytoplankton biomass, in returning nitrogen to the inorganic pool it may also stimulate production.

There is limited evidence that the carbon and nitrogen cycles may become decoupled in the upper water column. Changes in particulate carbon/nitrogen ratios suggest that phytoplankton nitrogen may be returned to the euphotic zone as ammonium and nitrite whilst phytoplankton carbon is exported to depth. There are no data to establish the "extent" of this decoupling in either space or time, but it does imply that at a local scale the accepted paradigm for the nitrogenous nutrition of exported and of recycled carbon may not be applied with total confidence.

We have noted that HNLC systems cannot be considered as a single mechanism, nor can single limiting factors be defined for primary production in these systems. This observation is not new; Hart (1934) wrote, 'It cannot be too strongly emphasised that in all probability phytoplankton production is always governed by a complex of inter-dependent factors, rather than by one or two which are clearly definable'. The search for easily identified single limiting factors probably derives from the present requirement for relatively simple models of large-scale biogeochemical processes. We need now to provide tractable multifactoral, and ideally generic, models which more accurately reflect the interacting controls.

The Southern Ocean itself appears to be a mosaic of regions of high and low nutrient input, high and low primary production, and high and low phytoplankton biomass (Banse, 1996). For the Southern Ocean as a whole, the only consistent factor appears to be the reduced value (low "bioavailability") of nitrate as an inorganic nitrogen source for phytoplankton growth. From this perspective, the system can be viewed as being one in which phytoplankton growth is strongly dependent on reduced nitrogen sources, especially ammonium, and the availability and rate of resupply of these nutrients may well be limiting to growth.

\section{ACKNOWLEDGEMENTS}

We are grateful to a number of colleagues for the benefit of advice and discussion on which parts of this paper have been based. The final opinions expressed here are, of course, our 
responsibility, but we wish to thank A. Atkinson, J. Berges, M. Fasham, K. Flynn, R. Geider, G. Hays, M. Lucas, N. Owens, D. Robins and D. Thomas. We also benefited from papers and discussions at a JGOFS modelling workshop held in Oban, Scotland, in May 1997 (abstracts and discussion summaries are available on the JGOFS Web page http://ads.smr.uib.no/jgofs/jgofs.htm). T. Trull and three referees provided helpful comments on an earlier version of the paper.

\section{REFERENCES}

Banse, K. 1996. Low seasonality of low concentrations of surface chlorophyll in the subantarctic water ring: underwater irradiance, iron, or grazing? Prog. Oceanogr., 37, 241-291.

Capriulo, G. M., E. B. Sherr and B. F. Sherr. 1991. Trophic behaviour and related feeding activities of heterotrophic marine protists. In Reid, P. C., C. M. Turley and P. H. Burkill, eds. Protozoa and their role in marine processes. Berlin, Springer-Verlag, 219265.

Coale, K. H. and 18 others. 1996. A massive phytoplankton bloom induced by an ecosystem-scale iron fertilization experiment in the equatorial Pacific Ocean. Nature, 383 (6600), 495-501.

Copin-Montegut, C. and G. Copin-Montegut. 1983. Stoichiometry of carbon, nitrogen and phosphorus in marine particulate matter. Deep-Sea Res., Ser. A, 30(1), 31-46.

Davies, A. G. 1990. Taking a cool look at iron. Nature, 345(6271), 114-115.

De Barr, H. J.W. and 6 others. 1995. Importance of iron for phytoplankton blooms and carbon dioxide drawdown in the Southern Ocean. Nature, $373(6513), 412-415$.

Dugdale, R. C. and J. J. Goering. 1967. Uptake of new and regenerated forms of nitrogen in primary productivity. Limnol. Oceanogr., 12 (2), 196-206.

El-Sayed, S. Z. 1984. Productivity of the Antarctic waters - a reappraisal. In Holm-Hansen, O., L. Bolis and R. Gilles, eds. Marine phytoplankton and productivity. Berlin, Springer-Verlag, 19-34.

Eppley, R.W. 1972. Temperature and phytoplankton growth in the sea. Fish. Bull. (NOAA), 70(4), 1062-1090.

Eppley, R.W. and B.J. Peterson. 1979. Particulate organic matter flux and planktonic new production in the deep ocean. Nature, 282(5740), 677-680,

Flynn, K. J. 1991. Algal carbon-nitrogen metabolism: a biochemical basis for modelling the interactions between nitrate and ammonium uptake. 7. Plankton Res., 13, 373-387.

Flynn, K. J., M. J. R. Fasham and C. R. Hipkin. 1997. Modelling the interactions between ammonium and nitrate uptake in marine phytoplankton. Philos. Trans. R. Soc. London, Ser. B, 352, 1-22.

Glibert, P. M., D. C. Biggs and J. J. McCarthy. 1982. Utilization of ammonium and nitrate during austral summer in the Scotia Sea. Deep-Sea Res., Ser. A, 29 (7), 837-850.

Hart, T.J. 1934. On the phytoplankton of the south-west Atlantic and the Bellingshausen Sea, 1929 -31. Discovery Rep. 8.

Hein, M. and K. Sand-Jensen. 1997. $\mathrm{CO}_{2}$ increases oceanic primary production. Nature, 388(6642), 526-527.

Hoch, M. P. and D. L. Kirchman. 1995. Ammonium uptake by heterotrophic bacteria in the Delaware estuary and adjacent coastal waters. Limnol. Oceanogr., 40(5), 886-897.

Jacques, G. 1983. Some ecophysiological aspects of the Antarctic phytoplankton. Polar Biol., 2(1), 27-33.

Jennings, J. C., Jr, L. I. Gordon and D. M. Nelson. 1984. Nutrient depletion indicates high primary productivity in the Weddell Sea. Nature, 309 (5963), 51-54.

Koike, I., O. Holm-Hansen and D. G. Biggs. 1986. Inorganic nitrogen metabolism by Antarctic phytoplankton with special reference to ammonium cycling. Mar. Ecol. Prog. Ser., 30, 105-116.

Loeb, V. and 6 others. 1997. Effects of sea-ice extent and krill or salp dominance on the Antarctic food web. Nature, 387 (6636), 897-900.

Longhurst, A. R. 1991. Role of the marine biosphere in the global carbon cycle. Limnol. Oceanogr., 36(8), 1507-1526.

Longhurst, A., S. Sathyendranath, T. Platt and C. Caverhill. 1995. Estimate of global primary production in the ocean from satellite radiometer data. J. Plankton Res., 17 (6), 1245-1271.

Löscher, B. M., H. J.W. de Baar, J.T. M. de Jong, C. Veth and F. Dehairs. 1997. The distribution of $\mathrm{Fe}$ in the Antarctic Circumpolar Current. Deep-Sea Res., Ser. II, 44(1-2), 143-187.

Martin, J. H. 1990. Glacial-interglacial $\mathrm{CO}_{2}$ change: the iron hypothesis. Paleoceanography, 5(1), 1-13.

Mitchell, B. G. and O. Holm-Hansen. 1991. Observations and modelling of the Antarctic phytoplankton crop in relation to mixing depth. Deep-Sea
Res., Ser. A, 38(8-9), 981-1007.

Peng, T. -H. and W. S. Broecker. 1991. Dynamic limitations on the Antarctic iron fertilization strategy. .Nature, 349(6306), 227-229.

Priddle, J., I. Hawes, J. C. Ellis-Evans and T. J. Smith. 1986. Antarctic aquatic ecosystems as habitats for phytoplankton. Biol. Rev. Cambridge Philos. Soc., 61 (3), 199-238.

Priddle, J., J. L. Watkins, D. J. Morris, C. Ricketts and F. Buchholz. 1990. Variation of feeding by krill in swarms. J. Plankton Res., 12 (6), 1189-1205.

Priddle, J., V. Smetacek and U.V. Bathmann. 1992. Antarctic marine primary production, biogeochemical carbon cycles and climate change. Philos. Trans. R. Soc. London, Ser. B, 338(1285), 289-297.

Priddle, J. and 7 others. 1995. Nutrient cycling by Antarctic marine microbia plankton. Mar. Ecol. Prog. Ser., 116, 181-198.

Priddle, J., M. J. Whitehouse, A. Atkinson, A. S. Brierley and E. J. Murphy. 1997. Diurnal changes in near-surface layer ammonium concentration - interplay between zooplankton and phytoplankton. 7. Plankton Res. $19(9), 1305-1330$.

Priddle, J., I. L. Boyd, M. J. Whitehouse, E. J. Murphy and J. P. Croxall.In press. Estimates of Southern Ocean primary production - constraints from predator carbon demand and nutrient drawdown. 7. Mar. Syst.

Raven, J. A. and R. J. Geider. 1988. Temperature and algal growth. New Phytol., $110(4), 441-461$

Redfield, A. C., B. H. Ketchum and F. A. Richards. 1963. The influence of organisms on the composition of seawater. In Hill, M.N., ed. The sea. New York, Wiley Interscience, 26-77.

Rice, A. L. and 6 others. 1986. Seasonal deposition of phytodetritus to the deepsea floor. Proc. R.Soc. Edinburgh, Sect. B, 88, 265-279.

Riebesell, U., D. A. Wolf-Gladrow and V. Smetacek. 1993. Carbon dioxide limitation of marine phytoplankton growth rates. Nature, 361(6409), 249-251.

Rönner, U., F. Sorensson and O. Holm-Hansen. 1983. Nitrogen assimilation by phytoplankton in the Scotia Sea. Polar Biol., 2(3), 137-147.

Sambrotto, R. N. and 9 others. 1993. Elevated consumption of carbon relative to nitrogen in the surface ocean. Nature, 363 (6426), 248-250.

Sarmiento, J. L. and J. C. Orr. 1991. Three-dimensional simulations of the impact of Southern Ocean nutrient depletion on atmospheric $\mathrm{CO}_{2}$ and ocean chemistry. Limnol. Oceanogr., 36 (8), 1928-1950.

Sathyendranath, S., A. D. Gouveia, S. R. Shetye, P. Ravindran and T. Platt. 1991. Biological control of surface temperature in the Arabian Sea. Nature, 349(6304), 54-56.

Scientific Committee on Oceanographic Research (SCOR). 1990. The Joint Global Ocean Flux Study (JGOFS): science plan. Halifax, N.S., Scientific Committee on Oceanographic Research. (JGOFS Report 5.

Smith, D. C., M. Simon, A. L. Alldredge and F. Azam. 1992. Intense hydrolytic enzyme activity on marine aggregates and implications for rapid particle dissolution. Nature, 359(6391), 139-142.

Smith, W. O. 1991. Nutrient distributions and new production in polar regions: parallels and contrasts between the Arctic and Antarctic. Mar. Chem., 35(1-4), 245-257.

Smith, W. O. and L. I. Gordon. 1997. Hyperproductivity of the Ross Sea (Antarctica) polynya during austral spring. Geophys. Res. Lett., 24(3), 233-236.

Tett, P. B. 1990. The photic zone. In Herring, P.J., A. K. Campbell, M. Whitfield and L. Maddock, eds. Light and life in the sea. Cambridge, Cambridge University Press, 59-87.

Tilzer, M. M., M. Elbrächter, W.W. Gieskes and B. Beese. 1986. Light-temperature interactions in the control of photosynthesis in Antarctic phytoplankton. Polar Biol., 5(2), 105-111.

Turner, S. M., P. D. Nightingale, L. J. Spokes, M. I. Liddicoat and P. S. Liss. 1996. Increased dimethylsulphide concentrations in sea water from in situ iron enrichment. Nature, $383(6600), 513-517$.

Wheeler, P. A. and S. A. Kokkinakis. 1990. Ammonium recycling limits nitrate use in the oceanic subarctic Pacific. Limnol. Oceanogr., 35(6), 1267-1278.

Whitehouse, M. J., J. Priddle, P. N. Trathan and M. A. Brandon. 1996. Substantial open-ocean phytoplankton blooms to the north of South Georgia, South Atlantic, during summer 1994. Mar. Ecol. Prog. Ser., 140(1-3), 187-197.

Williams, P. J. LeB. and J. E. Robertson. 1991. Overall planktonic oxygen and carbon dioxide metabolisms: the problem of reconciling observations and calculations of photosynthetic quotients. 7. Plankton Res., 13, Supplement, 153-169.

Williams, P.J. LeB., R. C.T. Rainé and J. R. Bryan. 1979. Agreement between the ${ }^{14} \mathrm{C}$ and oxygen methods of measuring phytoplankton production: reassessment of the photosynthetic quotient. Oceanol. Acta, 2(4), 411-416.

Zeebe, R. E., H. Eicken, D. H. Robinson, D. Wolf-Gladrow and G. S. Dieckmann. 1996. Modelling the heating and melting of sea ice through light absorption by microalgae. f. Geophys. Res., 101 (C1), 1163-1181. 